\title{
Poroscopy - The Study of Sweat Pores among Central Indian Population
}

\author{
Dr. Vaishali Bhagwat ${ }^{1}$, D. Mahesh Kumar ${ }^{*}$, Dr. K Naga Vidya Lakshmi ${ }^{3}$
}

\author{
${ }^{1}$ Associate professor, Department of Anatomy, Government Medical College, Latur, Maharastra, India \\ ${ }^{2}$ Assistant Professor Department of Anatomy, RKDF Medical College Hospital \& Research Center, Bhopal, Madhya Pradesh, India \\ ${ }^{3}$ Reader Department of Anatomy, VISHNU Dental College, Bhimavaram, Andhra Pradesh, India
}

\section{Abstract}

The study that deals with the scrutiny of sweat pores is known as Poroscopy. They were located as little openings over the frictional ridge skin near the distal end of digits \& in palms and soles. The study was conducted in central India among 400first year MBBS students of both sexes within the age limit of 18 to 23. Thumb prints of left hand were taken with Kores printer's ink over the executive bond paper and are then processed with Ninhydrin chemical. The Latent prints thus obtained are cautiously scrutinized using light source microscope. Prints are observed for number of round shaped pores per $1 \mathrm{~cm}$ ridge and noted carefully. Images were captured with digital camera. Largest number of round shaped pores per $\mathrm{cm}$ ridge on left hand thumb impression were ranging from 2-4 were identified among both the sexes. It has also been observed that males presented highest number of circular or round pores with a range of $2-4$ in $1 \mathrm{~cm}$ ridge as compared to females. Thus the poroscopic study based on the shapes of pores in $1 \mathrm{~cm}$ ridge of thumb prints plays a significant role in sex determination

Keywords: Sweat Pores Population, Poroscopy, Finger Prints.

Copyright @ 2020: This is an open-access article distributed under the terms of the Creative Commons Attribution license which permits unrestricted use, distribution, and reproduction in any medium for non-commercial use (NonCommercial, or CC-BY-NC) provided the original author and source are credited.

\section{INTRODUCTION}

Famous Frenchman Edmond Locard established the minimum number of minutia necessary for fingerprint identification [1-4]. One of the important most purposes of collection of physical evidence is to establish the identification of an individual for a particular person. The term Identification is used here is generally denotes individualization.

Imprints left on the volar surface of the fingers skin are known as finger prints that are seen as raised dermal ridges and furrows alternatively with adiversity in patterns having miniature sweat pores existing on the surface of dermal ridges [5]. When epidermis gets crumbled by any sort of damage like burns or long term water submerge these ridges serves as a tool for identification [6]. The examination of two parts of ridges on the frictional skin surface i.e. pores and the edge is rid geology. Poroscopy is the study that deals with the scrutiny of sweat pores

Edmond Locard a French criminologist also considered as "Father of Poroscopy" in 1912 has noticed that unlike ridges, pores as well are perpetual, entrenched and discrete and they are useful in specification of an individual [7]. He proposed that the recognition can be anticipated by pore size, shape, relative positioning $\&$ frequency of the poreappearance.

\section{Development of Finger Prints}

Embryo logically finger print motif develops in between $5^{\text {th }}$ to $6^{\text {th }}$ week of gestation and completely matures at the end of $21 \mathrm{st}$ week. The sweat glands begins to develop at around $14^{\text {th }}$ week of gestation and by the $24^{\text {th }}$ weekprocures adult architecture.

\section{Features of Finger Prints}

Features of finger print scan be categorized into three levels

- LEVEL ONE feature indicates pattern of ridge flow and basic particulars regarding framework

- $\quad$ LEVEL TWO feature specifies the details of trivia like endings of the ridge \&the bifurcations,

- LEVEL THREE features were received from the ridges $\&$ sweat pores located on the fingerprints $[8$, 9].

A pore is an aperture of sweat duct arising from the sweat gland ${ }^{7}$ in the subcutaneous layer 


\section{Characteristics of a Sweat Pore}

- Shapes of Pores conceivably oval, squarish, triangular rectangular, elliptical, pentagonal, rounded and rhomboid

- Pores perhaps aligned as single, double or in groups might be in the form of chain.

- Size of the pore may vary from small size to large size

- Situation of pores is either in the center of the ridge \&or periphery

- $\quad$ Number of pores may be 8-11[10].
- Pores may be open or closed type (Figure: 1). an open pore bisects the canyon placed between two ridges while closed pore is totally closed by the ridge [11]

Nearly 1400 pores can be observed in as single finger print. Various standard methods) such as powder dusting methods \& chemicals like Ninhydrin have been developed to study the latent prints patterns clearly. Latent prints are those prints that cannot be seen through the naked eye.

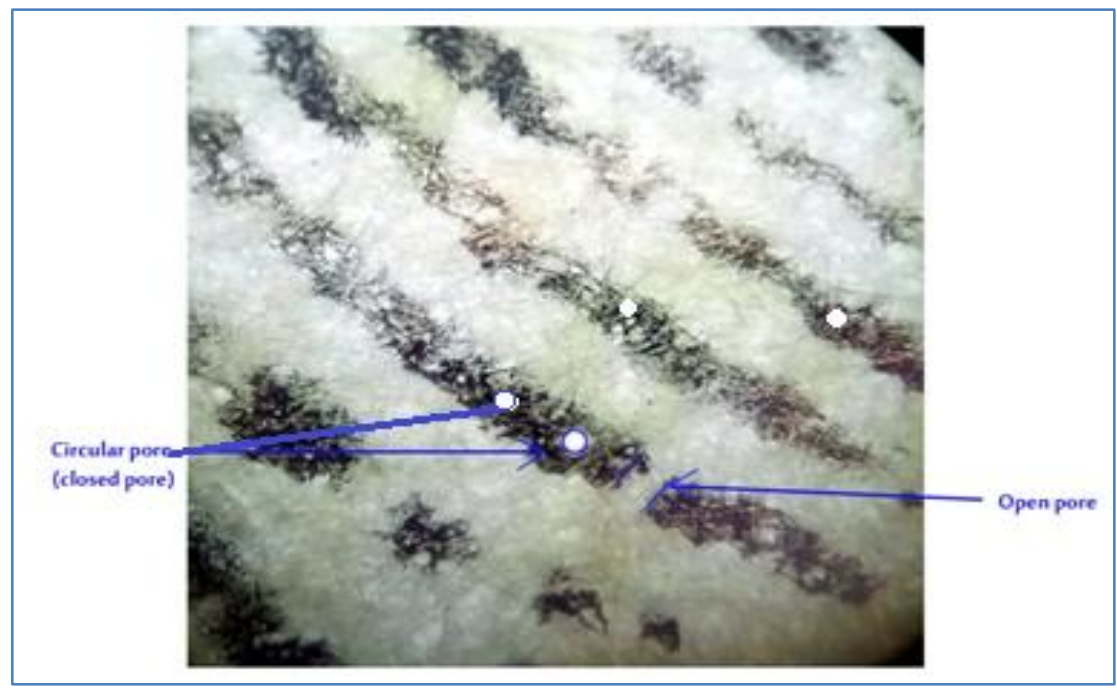

Fig-1: Showing circular or round pore of left thumb impression (10x)

\section{MATERIALS AND METHODS}

The study was conducted in central India among 400 first year MBBS students of both sexes within 18 to 23years age limit. Thumb prints of left hand were collected in the present research the student participants of the current study were requested to sanitize their hands rigorously using Dettol soap solution and wipe with dry napkin so that finger prints are free from any dust particles prior their collection. Thumb is pressed against ink and there after inked thumb finger should be swayed over the bond paper. In an alternative register the age, sex and name of every student was recorded at the same time while taking prints.

Printer's ink (Kores ink) is used to take Prints of left side thumb impressions and prints are then processed with Ninhydrin chemical. The Latent prints thus obtained are cautiously scrutinized using light source microscope.

List of the items utilized for bilateral finger prints of thumb from the participants were as follows:

- Kore's Printer's ink

- Ninhydrin Chemical -The best technique for bond paper prints

- Royal executive bond papers.

- Compound microscope (Binocular) with light source.
- In Accordance with forensic medicine department the rubber roller was employed to spread the ink on glass.

\section{Ninhydrin procedure}

Oden and Von Hofsten were the proponents of Ninhydrinuse in forensic for latent print development This technique works on principle that the Ninhydrinreact with fingerprint solid residues like amino acids, proteins \&polypeptides developing Ruhemann's purple. Several methods can be employed for the application of Ninhydrin solution such as dipping spraying, or swabbing. Acceleration of the procedure is done by utilizing heatof $80^{\circ}$ Fahrenheit in $80 \%$ relative humidity [12]

\section{Observations of left side thumb finger prints under a microscope}

The below listed characteristics of sweat pores were seen under microscope with10x cha are examined in both males and females.

1. Highest number of Round/Circular Shapes pores were identified first in both male and female sex and later least number of pores are noted.

\section{RESULTS}

As depicted in Table 1 \& Chart 1 We noticed among $1 \mathrm{~cm}$ ridge the highest number of round/circular 
pores are $2-4$. Less than 2 and greater than 4 were also observed in some prints of both sexes. 189 males out of 200 has presented $2-4$ round shape pore in $1 \mathrm{~cm}$ ridge the value is higher than female observations where only 183 females out of 200 has shown 2-4 round shape pores per $\mathrm{cm}$ ridge.
Table-1: Detail of pores left side thumb impression (circular / round shapes)

\begin{tabular}{|l|l|l|}
\hline & Male & Female \\
\hline$<2$ & 4 & 9 \\
\hline $2-4$ & 189 & 183 \\
\hline$>4$ & 7 & 8 \\
\hline TOTAL & 200 & 200 \\
\hline
\end{tabular}

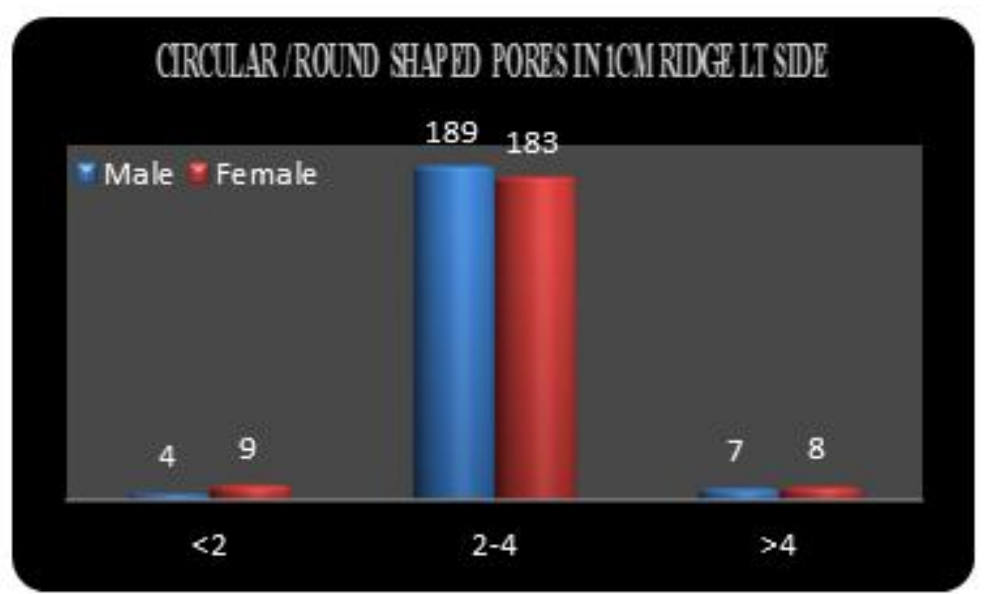

Chart-1: Showing Circular / Round shaped pores in $1 \mathrm{~cm}$ ridge LEFT side

Table-2: Comparison between male and female LEFT side thumb impression

\begin{tabular}{|c|c|c|c|c|c|c|}
\hline Mean & \multicolumn{2}{|l|}{ St.dev } & \multicolumn{2}{c|}{ Mean } & St.dev & P value \\
\hline 2.67 & 0.87 & 2.45 & 0.55 & 2.87 & 0.01 & 2.67 \\
\hline $\mathbf{2 . 5 4}$ & $\mathbf{0 . 5 5}$ & $\mathbf{2 . 6 7}$ & $\mathbf{0 . 8 7}$ & $\mathbf{1 . 6 6}$ & $\mathbf{0 . 1 0}$ & $\mathbf{2 . 5 4}$ \\
\hline
\end{tabular}

From the above table results it can be explained that Circular / Round pores means is higher in males in comparison with females, and it was statically significant (P-0.01).

Table-3: Correlation between male and female student's right side thumb pores (Paired Samples Correlations)

\begin{tabular}{|l|l|l|l|}
\hline & N & Correlation & Significance \\
\hline Round \& Round & 200 & -.082 & 0.245 \\
\hline
\end{tabular}

As shown in the above table the paired sample correlation between Circular / Round pores of male and female students was -0.82 which is not significant statistically.

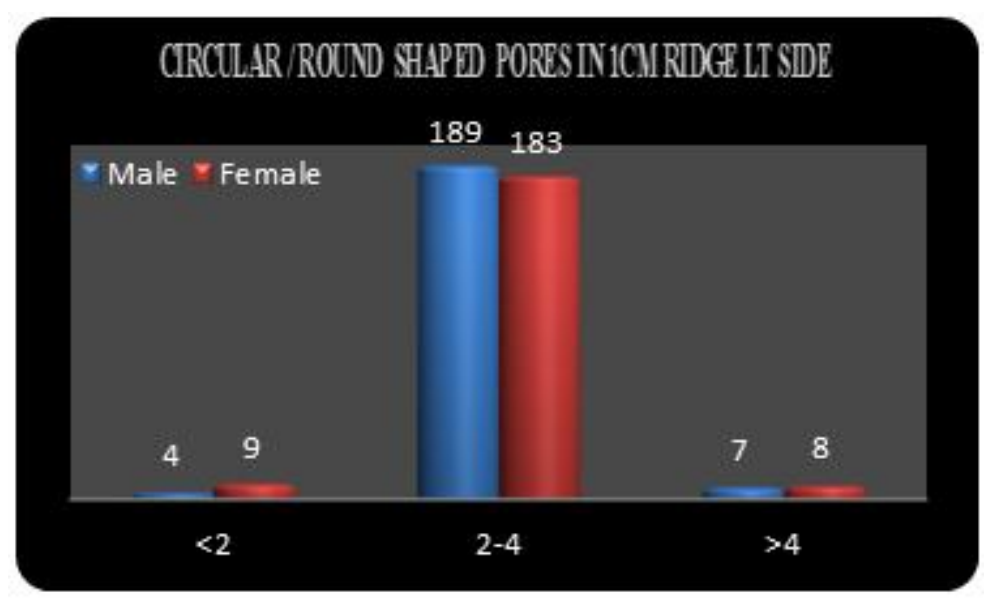

Chart 2: Showing Circular / Round shaped pores in 1 $\mathrm{cm}$ ridge LEFT side

\section{DISCUSSION}

Exceptional quality of finger prints of an individual's is that they remain unaffected throughout life hence gained its significance in several zones like forensic medicine\& science, anatomy and anthropology. The study that deals with the scrutiny of sweat pores is known as Poroscopy. They were located 
as little openings over the frictional ridge skin near the distal end of digits, $\&$ in palms and soles. Sweat pores shapes play a prominent role in sex determination of an individual.

According to present study highest range of round pores are $2-4$ in $1 \mathrm{~cm}$ ridge .on both right side and left side. Range in males are $94.5 \%$ and $91.5 \%$ in females on left side Percentage of round pores on left side range is higher in males as compared to females.

Bindra et al. [12] has observed medium sized pores are $23 \%-31 \%$ in $1 \mathrm{~cm}$ ridge in 100 sample size of both sexes. Haroon neem khan [13] observes 1-5 pores range per photomicrograph and average number is 1.96 per photomicrograph per 100 samples which is in correlation with the present study. According to the study of nagesh KR. Bathwal S and ashok B [14] circular and oval pores were more common. M. tafazoli [15] observed circular pores are $46.5 \%$ in 100 adult males46.

\section{CONCLUSION}

Poroscopic study based on the shapes of pores in $1 \mathrm{~cm}$ ridge of thumb prints is the finest method that plays a significant role not only in sex determination but also in the fields like forensic medicine \& science, anatomy and anthropology.

\section{REFERENCES}

1. Locard, E., La. (1903). dactyloscopie: identification des récidivistes par les empreintesdigitales, Mémoire de l'Académie des Sciences, Belles-lettres et Arts de Lyon, 147-161.

2. Locard, E. Le. (1906). Sixièmecongrèsd'anthropologiecriminelle,

Archives d'AnthropologieCriminelle, de MédecineLégale et de PsychologieNormale et Pathologique, 21, 865-873.

3. Locard, E. (1909). L'Identification des Récidivistes, Paris: A. Maloine.

4. Locard, E. (1911). Les laboratoires de police, Archives Internationales de MédecineLégale, 2, $105-117$.
5. Wijerathne, B. (2015). Poroscopy: an important research field in Medicine and Physical Anthropology. Anuradhapura Medical Journal, 9(2).

6. Leydier, G., Chunk Leblanc, R. C. M. P., \& Prince Rupert, B. C. (2004). Finger Tips: Use of dermal skin for identification. Identification Canada, 27(2), 29-30.

7. Czarnecki, E. (1995). Poroscopy An overview.reprinted from the april-june.scafo online article, July-August 11(4), 1-3.

8. Malathi, S, Meena, C. (2010). A novel approach for fingerprint recognition based on pores. International Journal of computer science and research, $1(1), 1014$.

9. Maltoni, D., Maio, D., Jain, A. K., \& Prabhakar, S. (2009). Handbook of fingerprint recognition. Springer Science \& Business Media.

10. Chatterjee, S.K. (1963). Edgeoscopy.International criminal police review, 186,149-145

11. Jain, A., Chen, Y., Dermirkus, M. Pores and ridges. (2007). Finger print matching using level 3 features. IEEE Trans pattern anal mach intell, 29(1), 15-27.

12. Bindra, B., Jasuja, O. P., \& Singla, A. K. (2000). Poroscopy: A method of personal identification revisited. Anil Aggrawal's Internet Journal of Forensic Medicine and Toxicology, 1(1).

13. Khan, H. N. (2012). Identification from edgeoscopy and poroscopy in the examination of partial fingerprints and their significance in crime investigation.

14. Nagesh, K. R., Bathwal, S., \& Ashoka, B. (2011). A preliminary study of pores on epidermal ridges: Are there any sex differences and age related changes?.Journal of forensic and legal medicine, 18(7), 302-305.

15. Tafazoli, M., Mahdavi Shahri, N., Ejtehadi, H., Haddad, F., Jabbari Nooghabi, H., Mahdavi Shahri, M., \& Naderi, S. (2013). Biological variability of sweat gland pores in the fingerprints of a Fars Iranian family from Khorasan Razavi province, Iran. Anatomical Sciences Journal, 10(2), 99-104. 